DOI: http://dx.doi.org/10.25181/jofsa.v2i1.788

Journal of Food System and Agribusiness Vol. 2 (1): 8-16

\title{
RISIKO PRODUKSI USAHATANI PADI DI KABUPATEN LAMPUNG TIMUR
}

\author{
THE RISK OF PRODUCTION OF PADDY RICE FARMING IN THE EAST LAMPUNG \\ REGENCY
}

\author{
Ainul Mardliyah ${ }^{2)}$ \\ ${ }^{2)}$ Pengajar Program Studi Agribisnis STIPER Dharma Wacana Metro \\ E-mail : ainulsoekoyo@gmail.com
}

\begin{abstract}
This research was to analyze the risk of production of paddy rice farming which received the Tertiary Irrigation (TI) optimization policy as compared to that without the Tertiary Irrigation (TI) optimization policy. This research was conducted in the village of Tulusrejo Pekalongan District of East Lampung regency. This research employed simple random sampling to collect the sample. The sample totaled 41 farmers consisting of 27 farmers who received the JIT optimization policy and 14 farmers who did not get the policy. This research was conducted from December 2016 to January 2017. Coefficient of Variation (CV) and t-test analysis were used to figure out the answer. The results showed that the risk of paddy rice production of farming which received the Tertiary Irrigation (TI) optimization policy is smaller than that which did not get the policy, although statistically it was not significantly different.
\end{abstract}

Keywords: irrigation, paddy rice, the risk of production.
Disubmit :30 April 2018
Diterima:30 Maret 2018,
Disetujui :1 April 2018

\section{PENDAHULUAN}

Pembangunan pertanian di Indonesia memiliki sasaran dalam menciptakan ketahanan pangan, meningkatkan nilai tambah dan daya saing produk pertanian serta meningkatkan kesejahteraan petani terutama pada komoditi bahan makanan pokok seperti padi. Usaha untuk meningkatkan produksi beras diupayakan melalui peningkatan produktivitas disamping peningkatan luas lahan (Asnawi, 2017), serta stabilitas produksi (Yulianto, 2017). Peningkatan produktivitas bisa dilakukan dengan melaksanakan rehabilitasi jaringan irigasi seperti: bendungan, saluran primer dan sekunder, kotak bagi, bangunan-bangunan ukur, dan saluran tersier serta saluran tingkat usaha tani (TUT), hal ini dilakukan untuk memungkinkan usahatani padi dapat dikembangkan dengan baik (Lamusa, 2012).

Pemerintah memiliki peran dalam penyediaan dan perbaikan jaringan irigasi untuk meningkatkan produktivitas padi. Salah satu propinsi penghasil padi di Indonesia adalah Propinsi Lampung. Pada tahun 2015 Propinsi Lampung memiliki produksi padi sebesar 3.641.895 ton/ha, dimana Propinsi Lampung menjadi daerah penghasil atau sentra tanaman padi nomor tujuh di Indonesia (BPS, 2016).

Kabupaten Lampung Timur merupakan salah satu daerah yang memiliki jumlah produksi padi sebesar 509.949 ton pada tahun 2013 (BPS 2014). Keberhasilan pertanian Ainul Mardliyah (Risiko Produksi Usahatani Padi Di Kabupaten Lampung Timur) 
padi perlu adanya dukungan berupa tersedianya sarana dan prasarana irigasi yang cukup untuk pengairan, serta efisiensi dalam penyaluran air irigasi (Purwanto, 2015). Luas lahan pengairan (irigasi) di Kabupaten Lampung Timur sebanyak 33.560 ha dan lahan non irigasi sebesar 29.484 ha (Dinas Pertanian Lampung, 2016).

Salah satu daerah penghasil padi di Kabupaten Lampung Timur adalah Kecamatan Pekalongan. Berdasarkan data BP3K Kecamatan Pekalongan pada tahun 2015 Kecamatan Pekalongan memiliki luas panen padi sebesar $2.640 \mathrm{Ha}$ dengan jumlah produksi padi sebesar 16.104 ton (BP3K Pekalongan, 2016). Desa yang mempunyai Perkumpulan Petani Pemakai Air (P3A) di Kecamatan Pekalongan adalah Desa Tulusrejo yang berasal dari sungai sekampung bunut. Desa Tulusrejo memiliki P3A dengan nama tirto kencono dengan luas lahan baku seluas $237 \mathrm{Ha}$ dan lahan fungsi seluas $210 \mathrm{Ha}$. Kondisi sarana irigasi saat ini banyak mengalami rehabilitasi.

Kebijakan optimalisasi Jaringan Irigasi Tersier (JIT) telah dijalankan dari tahun 2013 diharapkan dapat meningkatkan produksi padi di Desa Tulusrejo Kecamatan Pekalongan Kabupaten Lampung Timur dan mampu melaksanakan swasembada pangan nasional. Namun ada beberapa kendala atau permasalahan yakni benih tidak sesuai dengan keadaan wilayah dan perbedaan pengairan berdampak pada jumlah air yang diterima petak-petak sawah untuk usahatani padi di lokasi tersebut tidak sama sehingga petani harus menanggung risiko dalam usahatani seperti risiko produksi. Penelitian ini bertujuan untuk mengetahui risiko produksi usahatani padi yang mendapatkan kebijakan Optimalisasi Jaringan Irigasi Tersier (JIT) dengan yang tidak mendapatkan kebijakan Optimalisasi Jaringan Irigasi Tersier (JIT) di Desa Tulusrejo Kecamatan Pekalongan Kabupaten Lampung Timur.

\section{METODE}

Penelitian dilaksanakan di Desa Tulusrejo Kecamatan Pekalongan Kabupaten Lampung Timur. Pemilihan lokasi ini dilakukan sengaja (purposive) dengan pertimbangan daerah ini merupakan salah satu desa yang mendapatkan kebijakan optimalisasi Jaringan Irigasi Tersier (JIT). Metode Pengambilan sampel dilakukan dengan menggunakan metode secara acak sederhana (simple random sampling). Sampel sebanyak 41 petani dimana petani yang mendapatkan JIT sebanyak 27 orang, dan petani yang tidak mendapatkan JIT sebanyak 14 orang. Waktu penelitian dilakukan pada bulan Desember 2016 - Januari 2017. Metode yang digunakan adalah metode survei. Data yang digunakan dalam penelitian ini adalah data primer dan data sekunder. Data primer diperoleh melalui wawancara langsung kepada petani dengan menggunakan kuesioner. Data sekunder didapatkan dari instansi atau lembaga terkait.

Untuk mengetahui risiko produksi usahatani padi sawah dianalisis dengan menggunakan koefisien variasi (CV). Cara ini dilakukan dengan menggunakan data produksi yang diperoleh pada usahatani padi. Secara sistematis risiko produksi dirumuskan sebagai berikut :

$$
\begin{aligned}
& \mathrm{CV}=\frac{\sigma}{\bar{Q}} \\
& \text { Keterangan : } \\
& \mathrm{CV}=\text { koefisien variasi } \\
& \sigma=\text { standar deviasi } \\
& \bar{Q}=\text { rata-rata produksi }(\mathrm{kg})
\end{aligned}
$$

Besarnya nilai koefisien variasi menunjukkan besarnya risiko relatif usahatani. Nilai koefisien variasi yang kecil menunjukkan variabilitas nilai rata-rata pada karakteristik tersebut rendah. Hal ini menggambarkan risiko yang akan dihadapi petani untuk memperoleh produksi atau harga rata-rata tersebut rendah (Kurniati, 2014). Sebaliknya, 
nilai koefisien variasi yang besar menunjukkan variabilitas nilai rata-rata pada karakteristik tersebut tinggi. Hal ini menggambarkan risiko yang akan dihadapi petani untuk memperoleh produksi rata-rata tersebut besar. Penentuan batas bawah ini untuk mengetahui jumlah hasil terbawah tingkat hasil yang diharapkan, rumus perhitungan batas bawah adalah:

$$
\mathrm{L}=\mathrm{E}-2 \mathrm{~V}
$$

Keterangan:

$\mathrm{L}=$ batas bawah produksi

$\mathrm{V}=$ standar deviasi (simpangan baku)

$\mathrm{E}=$ rata-rata produksi yang diperoleh

Selanjutnya untuk menguji hipotesis dengan uji beda sebagai berikut:

- Ho : $C V_{j i t}=C V_{\text {non } j i t}$

Risiko produksi usahatani padi yang mendapatkan kebijakan optimalisasi Jaringan Irigasi Tersier (JIT) sama dengan yang tidak mendapatkan kebijakan Optimalisasi Jaringan Irigasi Tersier (JIT).

- $\mathrm{Ha}: C V_{j i t}>C V_{\text {non }}$ it

Risiko produksi usahatani padi yang mendapatkan kebijakan optimalisasi Jaringan Irigasi Tersier (JIT) lebih besar dari yang tidak mendapatkan kebijakan Optimalisasi Jaringan Irigasi Tersier (JIT).

Jika probabilitas $<\alpha$ berarti tolak Ho, dan probabilitas $>\alpha$ berarti terima Ho, dengan taraf kepercayaan $90 \%$. $\mathrm{t}_{\text {hitung }}$ dirumuskan sebagai berikut :

$\mathrm{T}$ hitung $=\frac{\left(\bar{x}_{1}-\bar{x}_{2}\right)}{\sqrt{\frac{s_{1}^{2}}{n_{1}}+\frac{s_{2}^{2}}{n_{2}}}}$

Keterangan:

$\mathrm{X}_{1}=$ rata-rata produksi usahatani padi yang mendapatkan kebijakan optimalisasi Jaringan Irigasi Tersier (JIT).

$\mathrm{X}_{2}=$ rata-rata produksi padi yang tidak mendapatkan kebijakan optimalisasi Jaringan Irigasi Tersier (JIT)

$\mathrm{S}_{1}=$ standar deviasi produksi padi yang mendapatkan kebijakan optimalisasi Jaringan Irigasi Tersier (JIT).

$\mathrm{S}_{2}=$ standar deviasi produksi yang tidak mendapatkan kebijakan optimalisasi Jaringan Irigasi Tersier (JIT)

\section{HASIL DAN PEMBAHASAN}

Penggunaan Benih dan Pupuk. Petani padi yang mendapatkan kebijakan optimalisasi Jaringan Irigasi Tersier (JIT) memperoleh benih varietas pertiwi dengan jumlah $25 \mathrm{~kg} / \mathrm{ha}$, namun benih tersebut sebagian besar tidak digunakan oleh petani padi dikarenakan tidak sesuai dengan kondisi persawahan di desa tersebut, sehingga petani lebih memilih membeli benih lain di kios (toko pertanian) yang sesuai dengan kondisi persawahan petani. Sedangkan petani padi yang tidak mendapatkan Kebijakan optimalisasi Jaringan Irigasi Tersier (JIT) memperoleh benih dengan membeli di kios (toko pertanian) dengan harga yang bervariasi, benih yang digunakan rata rata menggunakan benih ciherang. 
Pupuk yang digunakan petani yang mendapatkan dan yang tidak mendapatkan Jaringan Irigasi Tersier (JIT) adalah pupuk ponska, SP36, urea dan KCl. Distribusi ratarata penggunaan pupuk oleh petani padi dapat dilihat pada Tabel 1 berikut :

Tabel 1. Distribusi rata-rata penggunaan pupuk per usahatani

Di Desa Tulusrejo Kecamatan Pekalongan Kabupaten Lampung Timur

\begin{tabular}{lrrrrr}
\hline Jenis pupuk & \multicolumn{5}{c}{ Jumlah (kg) } \\
\cline { 2 - 5 } & \multicolumn{1}{c}{ Per usahatani } & \multicolumn{2}{c}{ Per ha } & Anjuran per ha \\
\cline { 2 - 5 } & Petani JIT & Petani non JIT & Petani JIT & Petani non JIT & \\
\hline Pupuk ponska & 130,00 & 67,85 & 282,64 & 141,35 & 300,00 \\
Pupuk SP36 & 146,00 & 60,38 & 317,39 & 125,79 & 150,00 \\
Pupuk urea & 187,00 & 101,78 & 406,52 & 212,04 & 400,00 \\
Pupuk KCL & 5,00 & 29,64 & 11,08 & 61,75 & 100,00 \\
\hline
\end{tabular}

Sumber: Data Primer, 2017.

Berdasarkan tabel 1 menunjukan bahwa penggunaan pupuk ponska, pupuk urea, dan pupuk $\mathrm{KCl}$ petani padi yang mendapatkan Jaringan Irigasi Tersier (JIT) lebih besar dari petani yang tidak mendapatkan JIT karena petani JIT mendapat bantuan benih pertiwi yang tidak sesuai dengan kondisi daerah setempat sehingga petani lebih banyak menggunakan pupuk untuk menaikkan produksi padi, hal ini selaras dengan Fauziyah (2013) yang menyatakan bahwa jika penggunaan input ditingkatkan, maka dipastikan petani akan dapat menghasilkan produksi yang lebih tinggi.

Penggunaan pestisida. Pestisida merupakan suatu bahan atau campuran bahan untuk mencegah, membasmi, menolak atau mengurangi hama yang menyerang tanaman. Penggunaan pestisida pada petani padi berupa fungisida (Villia, Score, Gandasil) insektisida (Sevin, Regent, Furadan) dan herbisida (Gramason, Roundup).

Penggunaan tenaga kerja. Pemakaian tenaga kerja digunakan untuk kegiatan pengolahan lahan, persemaian, penanaman, pemupukan, penyiangan, penyemprotan dan pemanenan. Tenaga kerja tersebut terdiri dari tenaga kerja wanita dan tenaga kerja pria yang di samaratakan dalam satuan hari orang kerja (hok) dengan standar jam kerja sebanyak 8 jam kerja per hari berdasarkan tingkat upah kerja yang berlaku. Penggunaan tenaga kerja mayoritas berasal dari luar keluarga (lk) sehingga petani harus mengeluarkan biaya untuk membayar upah tenaga kerja sebesar Rp.60.000,00 dengan lama jam kerja 8 jam/hari. Penggunaan tenaga kerja di daerah penelitian dapat dilihat pada tabel 2 sebagai berikut :

Tabel 2. Penggunaan tenaga kerja per usahatani padi Di Desa Tulusrejo, 2017

\begin{tabular}{lcccl}
\hline \multirow{2}{*}{ Jenis kegiatan } & \multicolumn{4}{c}{ Penggunaan tenaga kerja } \\
\cline { 2 - 5 } & LK (HOK) & DK (HOK) & Jumlah (HOK) & $(\%)$ \\
\hline Pengolahan tanah & 3 & 0 & 3 & 10,34 \\
Penanaman & 5 & 3 & 8 & 27,58 \\
Pemupukan & 4 & 0 & 4 & 13,79 \\
Penyiangan & 5 & 2 & 7 & 24,13 \\
Penyemprotan & 4 & 0 & 4 & 13,79 \\
Panen & 4 & 0 & 4 & 13,79 \\
\hline Jumlah & 25 & 5 & 30 & 100,00 \\
\hline
\end{tabular}

Sumber : Data Primer, 2017

Berdasarkan tabel 2 menunjukan bahwa jumlah tenaga kerja yang digunakan baik yang mendapatkan JIT dan non JIT tersebut berasal dari tenaga kerja dalam keluarga dan luar keluarga. Tenaga kerja yang banyak di gunakan dalam usahatani padi adalah tenaga kerja yang digunakan untuk kegiatan penanaman yaitu berjumlah 5 orang dari luar keluarga (LK) dan 3 orang dari dalam keluarga (DK) dengan persentase 27,58\%. 
Penggunaan peralatan. Petani padi mengunakan alat-alat pertanian yang masih sederhana seperti cangkul, handsprayer, sabit, golok, karung, ember. Rata-rata umur ekonomis dan penyusutan untuk peralatan petani padi sebesar 5 tahun dengan besarnya rupiah Rp 38.488 per tahun. Penyusutan peralatan dapat dilihat pada tabel 3.

Tabel 3. Penggunaan peralatan dalam usahatani padi pada lahan petani yang mendapatkan kebijakan optimalisasi JIT , 2017

\begin{tabular}{lrrcr}
\hline Peralatan & Harga (Rp) & \multicolumn{1}{c}{ Jumlah } & Umur ekonomis(thn) & Penyusutan(Rp/thn) \\
\hline Cangkul & 60.000 & 29 & 5 & 12.889 \\
Sabit & 35.000 & 31 & 5 & 8.037 \\
Handsprayer & 250.000 & 27 & 5 & 50.000 \\
Gosrokan & 5.926 & 4 & 5 & 2.963 \\
Karung & 2.000 & 2280 & 2 & 148.148 \\
Ember & 15.000 & 80 & 5 & 8.889 \\
\hline Jumlah & & & & 230.926 \\
Rata-rata & & & & 38.488 \\
\hline
\end{tabular}

Sumber : Data Primer, 2017

Rata-rata umur ekonomis dan penyusutan untuk peralatan petani yang mendapatkan dan yang tidak mendapatkan kebijakan optimalisasi Jaringan Irigasi Tersier (JIT) tersebut adalah 5 tahun dan rata-rata rupiah sebesar Rp.40.214 per tahun, hal ini dapat dilihat pada tabel 4.

Tabel 4. Penggunaan peralatan dalam usahatani padi sawah pada lahan petani yang tidak mendapatkan kebijakan optimalisasi JIT, 2017

\begin{tabular}{lrrcr}
\hline Peralatan & Harga(Rp) & Jumlah & Umur ekonomis (thn) & Penyusutan(Rp/thn) \\
\hline Cangkul & 60.000 & 17 & 5 & 14.286 \\
Sabit & 35.000 & 16 & 5 & 8.000 \\
Handsprayer & 250.000 & 14 & 5 & 50.000 \\
Gosrokan & 40.000 & 7 & 5 & 10.000 \\
Karung & 2.000 & 1.050 & 2 & 150.000 \\
Ember & 15.000 & 42 & 5 & 9.000 \\
\hline \multicolumn{1}{c}{ Jumlah } & & & & 241.286 \\
$\quad$ Rata-rata & & & & 40.214 \\
\hline
\end{tabular}

Sumber : Data Primer, 2017

Produksi. Produksi yang dihasilkan oleh petani sangat bervariasi, karena produksi yang dihasilkan tergantung pada luas lahan yang ditanam, modal yang dimiliki oleh petani, serta cuaca. Hal ini senada dengan Suryana et al., (2009) yang menyatakan bahwa beberapa permasalahan dalam usahatani padi adalah kepemilikan lahan yang relatif kecil, keterbatasan debit air, keterbatasan modal, dan tingkat serangan hama dan penyakit yang masih cenderung tinggi. Adapun produksi petani padi yang mendapatkan kebijakan optimalisasi Jaringan Irigasi Tersier (JIT) dan yang tidak mendapatkan kebijakan optimalisasi Jaringan Irigasi Tersier (JIT) dapat dilihat pada Tabel 5.

Tabel 5. Rata-rata produksi usahatani padi dalam satu musim tanam di Desa Tulusrejo Kecamatan Pekalongan Kabupaten Lampung Timur, 2017.

\begin{tabular}{lll}
\hline Uraian & Petani JIT & Petani non JIT \\
\hline Per usahatani & & \\
Luas lahan (ha) & 0,46 & 0,48 \\
Produksi (kg) & $2.459,25$ & $3.021,42$ \\
Harga (Rp) & $3.700,00$ & $3.700,00$ \\
\hline
\end{tabular}

Sumber : Data Primer, 2017 
Berdasarkan Tabel 5 dapat diketahui bahwa rata-rata produksi usahatani yang mendapatkan kebijakan optimalisasi Jaringan Irigasi Tersier (JIT) sebesar 2.459,25 kg dan yang tidak mendapatkan kebijakan optimalisasi Jaringan Irigasi Tersier (JIT) sebesar $3.021,42 \mathrm{~kg}$. Hal ini terlihat bahwa produksi usahatani padi yang mendapatkan kebijakan optimalisasi Jaringan Irigasi Tersier (JIT) lebih rendah dibandingkan produksi usahatani padi yang tidak mendapatkan kebijakan optimalisasi Jaringan Irigasi Tersier (JIT) ini terjadi karena petani yang mendapatkan kebijakan optimalisasi Jaringan Irigasi Tersier (JIT) mendapatkan bantuan berupa benih (pertiwi) yang tidak sesuai dengan kondisi persawahan di Desa Tulusrejo sehingga benih tersebut rentan terhadap serangan hama seperti wereng yang sedang mewabah pada musim tanam tersebut yang mengakibatkan produksi petani yang mendapatkan kebijakan optimalisasi JIT mengalami penurunan yang drastis. Selain itu ketika menanam benih tersebut pada musim hujan, sehingga tingkat serangan hama dan penyakit lebih tinggi yang akan mempengaruhi risiko produksi, hal ini senada dengan Suharyanto, S (2016) yang menyatakan bahwa risiko usahatani padi sawah pada musim hujan lebih tinggi daripada musim kemarau. Harga padi yang mendapatkan kebijakan optimalisasi dan yang tidak mendapatkan kebijakan optimalisasi JIT rata-rata sama sebesar Rp. 3.700/kg. Petani padi menjual hasil produksinya kepada pedagang pengumpul. Sistem penjualannya dengan cara menjual langsung hasil produksinya kepada pedagang pengumpul dan pihak pedagang langsung mengambil hasil produksinya di lahan sehingga biaya angkut ditanggung oleh pedagang pengumpul.

Risiko produksi. Risiko usahatani padi dapat dianalisis dengan menggunakan analisis koefisien variasi (CV). Perbandingan risiko produksi dilakukan dengan analisis koefisien variasi $(\mathrm{CV})$ pada Tabel 6.

Tabel 6. Perbandingan risiko produksi usahatani padi satu musim tanam di Desa Tulusrejo Kecamatan Pekalongan Kabupaten Lampung Timur, 2017.

\begin{tabular}{lrr}
\hline \multirow{2}{*}{ Uraian } & \multicolumn{2}{c}{ Risiko Produksi } \\
\cline { 2 - 3 } & \multicolumn{2}{c}{ JIT } \\
\hline Per usahatani & & \\
Nilai tengah (E) & $2.459,26$ & $3.021,43$ \\
Stdev (V) & $1.661,62$ & $2.081,49$ \\
L & $-863,97$ & $-1.141,54$ \\
CV & 0,68 & 0,69 \\
\hline Sumber : Data Primer, 2017
\end{tabular}

Sumber : Data Primer, 2017

Berdasarkan Tabel 6 untuk produksi padi terlihat bahwa nilai tengah (E) petani padi yang mendapatkan kebijakan optimalisasi Jaringan Irigasi Tersier (JIT) sebesar 2.459,26 $\mathrm{kg} / \mathrm{usahatani}$ artinya bahwa rata-rata produksi per usahatani yang dihasilkan petani selama satu musim tanam, dengan standar deviasi (V) sebesar 1.661,62 kg/usahatani, dan nilai CV sebesar 0,68 yang menunjukkan bahwa yang artinya bahwa rata-rata produksi per usahatani yang dihasilkan petani padi yang mendapatkan kebijakan optimalisasi Jaringan Irigasi Tersier (JIT) memiliki peluang kehilangan produksi akibat gagal panen sebesar 0,68. Batas bawah (L) produksi sebesar -863,97 yang artinya bahwa kemungkinan risiko produksi terendah atau kerugian terendah yang dihadapi yang artinya bahwa rata-rata produksi per usahatani yang dihasilkan petani padi yang mendapatkan kebijakan optimalisasi Jaringan Irigasi Tersier (JIT) setiap musim sebesar 863,97 $\mathrm{kg} / \mathrm{usahatani}$.

Ainul Mardliyah (Risiko Produksi Usahatani Padi Di Kabupaten Lampung Timur) 
Sedangkan nilai tengah dari produksi yang artinya bahwa rata-rata produksi per usahatani yang dihasilkan petani padi yang tidak mendapatkan kebijakan optimalisasi Jaringan Irigasi Tersier (JIT) sebesar 3.021,43 kg/usahatani yang artinya bahwa rata-rata produksi per usahatani yang dihasilkan petani selama satu musim tanam, dengan standar deviasi sebesar 2.081,49 kg/usahatani, dan nilai CV sebesar 0,69 yang menunjukkan bahwa petani padi yang tidak mendapatkan kebijakan optimalisasi Jaringan Irigasi Tersier (JIT) memiliki peluang kehilangan produksi sebesar 0,69 kg. Dengan batas bawah produksi (L) sebesar -1.141,54 yang artinya bahwa kemungkinan risiko produksi terendah atau kerugian terendah yang dihadapi petani padi sawah yang tidak mendapatkan kebijakan optimalisasi Jaringan Irigasi Tersier (JIT) setiap musim sebesar 1.141,54 $\mathrm{kg} / \mathrm{usahatani}$.

Hasil penelitian menunjukkan nilai dari standar deviasi (V) petani padi yang tidak mendapatkan kebijakan optimalisasi Jaringan Irigasi Tersier (JIT) lebih besar dibandingkan petani padi yang mendapatkan kebijakan optimalisasi Jaringan Irigasi Tersier (JIT). Hal ini terjadi karena petani padi yang tidak mendapatkan kebijakan optimalisasi JIT pada musim tanam tersebut jarang yang terserang hama wereng dan menggunakan benih ciherang yang sesuai dengan kondisi lahan petani sehingga produksi padi sawah mereka lebih besar dibandingkan produksi padi yang mendapatkan kebijakan optimalisasi JIT, walaupun petani yang tidak mendapatkan kebijakan optimalisasi Jaringan Irigasi Tersier (JIT) tidak mendapatkan jaminan ketersediaan air untuk mengairi lahan yang ditanami sehingga petani yang tidak mendapatkan air irigasi mereka harus menyewa mesin air untuk mengangkut/menambah intensitas debit air. Pengujian hipotesis dari analisis uji beda dari risiko produksi dapat dilihat pada Tabel 7.

Tabel 7. Hasil analisis uji beda dari risiko produksi petani padi

\begin{tabular}{lllll}
\hline Keterangan (per usahatani) & Petani JIT & Petani non JIT & $\mathrm{t}_{\text {hitung }}$ & Probabilitas \\
\hline Produksi & $2.459,25$ & $3.021,42$ & 0,876 & 0,352
\end{tabular}

Sumber: Data Primer, 2017

Berdasarkan Tabel 7 terlihat bahwa produksi padi yang mendapatkan kebijakan optimalisasi Jaringan Irigasi Tersier (JIT) sebesar 2.459,25 kg per usahatani dan produksi padi sawah yang tidak mendapatkan kebijakan optimalisasi Jaringan Irigasi Tersier (JIT) sebesar 3.021,42 kg per usahatani. Produksi padi sawah yang mendapatkan kebijakan optimalisasi Jaringan Irigasi Tersier (JIT) lebih rendah dibandingkan dengan produksi padi sawah yang tidak mendapatkan kebijakan optimalisasi Jaringan Irigasi Tersier (JIT), namun berdasarkan statistik terlihat bahwa hasil uji beda tidak berpengaruh secara nyata dengan $t_{\text {hitung }}$ sebesar 0,876 dan probabilitas sebesar 0,352 lebih besar dari 0,1 artinya terima Ho, tolak Ha dimana tidak terdapat perbedaan risiko produksi petani padi yang mendapatkan kebijakan optimalisasi Jaringan Irigasi Tersier (JIT) dan petani padi sawah yang tidak mendapatkan kebijakan optimalisasi Jaringan Irigasi Tersier (JIT). Hal ini terjadi karena risiko produksi sangat dipengaruhi oleh cuaca, dimana petani padi pada saat musim tanam tersebut mengalami serangan hama wereng, hal ini sesuai dengan pernyataan Heriani (2013) yang menyatakan bahwa risiko produksi berasal dari serangan hama dan penyakit yang menyerang secara mendadak dan bersifat meluas.

\section{SIMPULAN DAN SARAN}

\section{Simpulan}

Berdasarkan hasil penelitian maka dapat disimpulkan bahwa: 
Risiko produksi usahatani padi sawah yang mendapatkan kebijakan optimalisasi Jaringan Irigasi Tersier (JIT) lebih kecil dibandingkan dengan yang tidak mendapatkan kebijakan optimalisasi Jaringan Irigasi Tersier (JIT), walaupun secara statistik risiko produksi yang mendapatkan kebijakan optimalisasi JIT tidak berbeda secara nyata dengan risiko produksi yang tidak mendapatkan kebijakan optimalisasi JIT di Desa Tulusrejo Kecamatan Pekalongan Kabupaten Lampung Timur.

\section{Saran}

Berdasarkan hasil dan pembahasan, maka saran yang diajukan dalam penelitian ini adalah:

Pemerintah sebaiknya memperhatikan kembali tentang kebijakan yang dikeluarkan agar lebih tepat dengan situasi dan kondisi daerah yang akan menerima kebijakan tersebut sehingga petani bisa memperkecil rIsiko dalam berusahatani.

\section{Ucapan Terima Kasih}

Peneliti mengucapkan terima kasih kepada Sekolah Tinggi Ilmu Pertanian (STIPER) Dharma Wacana Metro yang telah memberikan kemudahan dan mendanai penelitian ini.

\section{DAFTAR PUSTAKA}

Asnawi, R. (2017). Peningkatan produktivitas dan pendapatan petani melalui penerapan model pengelolaan tanaman terpadu padi sawah di Kabupaten Pesawaran, Lampung. Jurnal Penelitian Pertanian Terapan, 14(1).

Badan Pusat Statistik. (2014). Data Produksi Tanaman Padi Sawah per-Kabupaten/kota. BPS. Lampung.

Badan Pusat Statistik. (2016). Data Produksi Padi Sawah Menurut Seluruh Propinsi di Indonesia. BPS. Jakarta.

BP3K Pekalongan. (2015). Nama P3A dan GP3A Kecamatan Pekalongan Kabupaten Lampung Timur.

BP3K Pekalongan. (2016). Data Luas Panen, Produktivitas dan Jumlah Produksi Padi Sawah. BP3K. Lampung Timur

Fauziyah, E., Hartoyo, S., Kusnadi, N., \& Kuntjoro, S. U. (2010). Analisis produktivitas usahatani tembakau di kabupaten Pamekasan. Jurnal Organisasi dan Manajemen, 6(2), 119-131.

Lamusa, A. (2010). Risiko usahatani padi sawah rumah tangga di daerah Impenso Provinsi Sulawesi Tengah. Agroland, 17(3).

Laporan Statistik Pertanian Tanaman Pangan. 2016. Data Luas Lahan Sawah Menurut Kabupaten/kota dan Jenis Pengairan Provinsi Lampung. Dinas Pertanian. Lampung.

Heriani, N., Zakaria, W. A., \& Soelaiman, A. (2013). Analisis keuntungan dan risiko usahatani tomat di Kecamatan Sumberejo Kabupaten Tanggamus. Jurnal IlmuIlmu Agribisnis, 1(2).

Ainul Mardliyah (Risiko Produksi Usahatani Padi Di Kabupaten Lampung Timur) 
DOI: http://dx.doi.org/10.25181/jofsa.v2i1.788

Journal of Food System and Agribusiness Vol. 2 (1): 8-16

Kurniati, D. (2012). Analisis risiko produksi dan faktor-faktor yang mempengaruhinya pada usahatani jagung (Zea Mays L.) di Kecamatan Mempawah Hulu Kabupaten Landak. Jurnal Social Economic of Agriculture, 1(3).

Purwanto, M. Y. J., \& Anika, N. (2012). Peningkatan Efisiensi dan Produksi Pangan dengan Pembangunan Sistem irigasi Pipa di Tingkat Tersier.

Suharyanto, S., Rinaldy, J., \& Arya, N. N. (2016). Analisis risiko produksi usahatani padi sawah di Provinsi Bali. AGRARIS: Journal of Agribusiness and Rural Development Research, 1(2), 70-77.

Suryana, A., Mardianto, S., Kariyasa, K., \& Wardhana, I. P. (2009). Kedudukan Padi Dalam Perekonomian Indonesia dalam Padi, Inovasi Teknologi dan Ketahanan Pangan. Buku, 1, 7-31.

Yulianto, yulianto. (2017). Ketahanan varietas padi lokal mentik wangi terhadap penyakit blas. Journal of Food System and Agribusiness (JoFSA), 1(1), 47-54. Retrieved from http://jurnal.polinela-srv.id/index.php/JOFSA/article/view/83 